\title{
MICROPEDOLOGIA DA ALTERAÇÃO EM PERFIS DE SOLOS COM B TEXTURAL NA REGIÃO DE LAVRAS, MINAS GERAIS ${ }^{(\mathbf{1})}$
}

\author{
M. P. C. LACERDA ${ }^{(2)}$, H. ANDRADE ${ }^{(3)}$ \& J . J . G. QUÉ MÉ NE UR ${ }^{(4)}$
}

\begin{abstract}
RESUMO
Na região de Lavras (MG), foram selecionados perfis de solos com horizonte B textural para a avaliação micropedológica dos processos de alteração e investigação de características de evolução pedológica vinculadas ao material de origem. Os solos com horizonte B textural foram selecionados para tal estudo, dado seu grau de evolução que permi te avaliar características herdadas da rocha original. Foram escolhidas classes de solos com B textural, desenvolvidos em relevo ondulado a forte ondulado, a partir de materiais geológicos litoquimicamente distintos: Perfil 1-Argissolo Vermel ho-Amarelo distrófico, originado por alteração de rochas do domínio geológico Granito de I tutinga; Perfil 2 -Argissolo Vermelho eutrófico, desenvolvido a partir de rochas do domínio geológico Diorito do Rosário; e Perfil 3 - Chernossolo Argilúvico férrico, desenvolvido a partir de rochas do domínio geológico Greenstone-belt de Lavras. Ao longo dos perfis de alteração selecionados, realizaram-se análises petrográficas dos fácies rocha fresca e rocha alterada, bem como análises micromorfológicas dos fácies alterito, de transição e sólum. Para avaliar os processos de alteração, observaram-se as reações de alteração e feições texturais, com auxílio da difração de raios-X com vistas em identi ficar a mineralogia da fração argila, numa discussão envolvendo material de origem versus processos de alteração pedogenética, possibilitando estabelecer a ordem de destruição dos minerais primários. A evolução dos processos de alteração ao longo dos perfis mostrou-se diretamente vinculada à textura, composição química e mineralógica dos materiais originais, refletindose nas características micromorfológicas e composição mineralógica dos horizontes que compõem cada perfil, especialmente o horizonte diagnóstico - B textural.
\end{abstract}

Termos de indexação: micromorfologia, mineralogia, petrografia, alteração pedogenética.

(1) Parte da Tese de Doutorado, apresentada pela primeira autora ao Curso de Pós-Graduação em Solos e Nutrição de Plantas do Departamento de Ciência do Solo da Universidade Federal de Lavras - DCS-UFLA, com financiamento da FAPEMIG. Recebido para publicação em novembro de 1999 e aprovado em julho de 2000.

(2) Pesquisadora da Empresa de Pesquisa Agropecuária de Minas Gerais - EPAMIG/CTSM. Recém-Doutor. Campus da UFLA. Caixa Postal 176, CEP 37200.000 Lavras (MG). Bolsista FAPEMIG. E-mail: marilusa@ufla.br.

(3) Professor do Departamento de Ciência do Solo da Universidade Federal de Lavras - UFLA. Caixa Postal 37. CEP $37200-000$ Lavras (MG). E-mail: handrade@ufla.br.

(4) Professor do Departamento de Geologia do Instituto de Geociências da Universidade Federal de Minas Gerais - DG/I GC/UF MG. Av. Antônio Carlos 6.627. Caixa Postal 2608. CEP 31270-901 Belo Horizonte (MG). 


\title{
SUMMARY: MICROPEDOLOGY OF ALTERATION IN PROFILES OF SOILS WITH ARGILLIC HORIZON IN THE REGION OF LAVRAS, MINAS GERAIS
}

\begin{abstract}
In theregion of Lavras, Minas Gerais, Brazil, soi Is profiles with argillic horizons were selected to eval uatethealterati ons which occurred during the process of soil formation and to investi gate pedogenetic characteristics rel ated to the parent material. Within this region, these soi ls occur on sloping and hilly landscapes. They were sel ected for this study because they preserve characteristics inherited from the original bedrocks. Three profiles formed from geologic material with different chemical composition were sel ected: Profile 1 - RedYellow Argisol devel oped from granitic rocks (Granito del tutinga); Profile 2 - Red Argisol formed from dioritic rocks (Diorito do Rosário); and Profile 3 - Argiluvic Chernosol formed from basic rocks of the Greenstone-Belt of Lavras. Throughout the layers of each profile, from theconsol idated bedrock to the sól um, studies werecarried out (petrographic analyses on theconsolidated and weathered bedrock, mi cromor phol ogical analyses of C, BC horizons and sól um) to investi gatetheprocesses of soil formati on by evaluating weathering reactions and textural features, with the aid of X-ray diffraction analyses to characterize clay mineral ogy. Based on the results obtained, the relationships between parent material and pedogenetic processes were assessed and the order of destruction of primary minerals established. The evolution of the alteration processes along the profiles was found to be directly linked to thetexture, chemical and mineral ogical composition of theparent materials, revealed in the micromorphological characteristics and mineralogical composition of the horizons constituents of each profile, particularly in the argillic horizon.
\end{abstract}

Index terms: micromorphol ogy, mineralogy, petrography, pedogenetic alteration.

\section{NTRODUÇÃO}

Na região de Lavras (MG), na área entre Ribeirão Vermel hoe Nazareno, ocorrem, segundo Quéméneur (1995), terrenos Arqueanos constituídos por gnaisses de composição trondhjemítica-tonalítica-granodiorítica (TTG) (GnaissePau da Bandeira), gnaisses de composição granodiorítica (Gnaisse Granodiorítico de Lavras) a granítica (Gnaisses Graníticos), granulitos (Granulitos Cál cio-Al calino Potássi cos Charnockitos e Gnaisses Charnockíti cos, Granulitos Trondhjemítico-Tonalítico - Enderbitos e Granulitos MáficoseUltramáficos) erochas básicas eultrabásicas relacionadas com as formações do tipo greenstonebel ts (Greenstone-belt Rio das Mortes e Greenstone belt de Lavras). Estas últimas apresentam maciços intrusivos de rochas de composição intermediária a básica, como o Diorito do Rosário e Gabro da Fazenda Martins. Do Proterozóico, relacionado com ocicl o geol ógi cotectono-orogenético Transamazônico, ocorre uma série de plútons intrusivos no Arqueano, tais como o Granito Transamazônico de I tutinga e Granodiorito Transamazônico, além de formações metassedimentares da Serra de Bom Sucesso (Supergrupo Minas) e de rochas metassedimentares na Serra de Ijaci, possivelmente pertencentes ao Grupo São J oão Del Rei. Todas as serras ao sul da área, em contato tectônico com este embasamento arqueano e proterozóico, pertencem às unidades metassedimentares do Grupo Carrancas, considerado como pós-transamazônico.

Os sol os diferenciados da região estão vinculados à grande diversidade geol ógica, correlacionando-se também com o relevo, por meio de diferenças de declividade (Andrade et al., 1998). Os L atossolos ocorrem em declividades de 0 a $12 \%$, os solos com horizonte B textural de 12 a $45 \%$ e, em declividades $>45 \%$, verifica-se a presença de Cambissolos e $\mathrm{N}$ eossol os Litóli cos. Classes distintas desses sol os são desenvolvidas de acordo com a diferenciação petrológica do material originário.

O estudo microscópico gera informações relevantes sobre a gênese dos solos, pois fornece a caracterização do material de origem e sua constituição mineralógica e permite observar as reações mineralógicas retrógradas, decorrentes das variações físico-químicas que ocorrem ao longo da evoluç̧ão do processo pedogenético (Loughnan, 1969). A análise micropedológica é utilizada na identificação, distribuição e inter-relação dos constituintes do solo, convenientemente separados em unidades de organização, tais como: peds, feições pedológicas e matriz ou fundo matricial, que inclui esquel eto, plasma e poros associados (Cady et al., 1986; Castro, 1989). O conjunto dessas informações permite, então, avaliar a evolução do processo pedogenético ao longo do perfil de alteração, desde a rocha fresca até o sólum. 
Apesar da rel evância do estudo micropedológico na gênese desol os, particularmente para a correlação com o material de origem, não existem trabal hos que contemplem tal tema na região de Lavras (MG). Assim, foram sel ecionados perfis das classes de sol os com B textural mais significativas erepresentativas da região, para a caracterização mi cropedológica dos processos de alteração, objetivando estabelecer características pedogenéticas associadas ao material de origem. Esses sol os foram selecionados para este estudo pelo seu grau de evolução, que permite preservar características químicas e mineralógicas herdadas do material parental. Aolongo de todos os horizontes dos perfis selecionados, desde a rocha fresca até o sólum, realizou-se a caracterização mineralógica, petrográfica e micromorfológica, identificando-se petrologicamente o material de origem e suas transformações mineralógicas e texturais ao longo da evol ução do perfil dealteração, numa discussão envol vendo processos pedogenéticos versus material originário.

\section{MATE RIAL E MÉTODOS}

\section{Perfis selecionados e métodos de campo}

Dada a grande diversidade geol ógica quea região apresenta, procurou-seselecionar perfis dealteração, a partir de materiais geológicos geoquimicamente discriminados, individualizados em domínios geológicos de composição ácida, intermediária e básica, com desenvol vimento de classes de solos com B textural bem distintas, para que a interpretação sobre a evolução das classes intermediárias desses solos pudesse ser posteriormente extrapolada.

A maior dificuldadeencontrada nesta etapa foi a seleção de perfis completos e autóctones, desenvolvidos a partir de rochas frescas, com evidências da evolução in situ dos processos de alteração ao longo dos horizontes pedogenéticos. 0 autoctonismo evidenciado no campo pela avaliação das características macromorfológicas ao longo dos perfis, desde a rocha fresca de origem até o sólum, teve sua corroboração por meio de análise da evol ução das fei ções texturais, do comportamento do complexo sortivo e caracterização geoquímica com balanço químico de massa, realizados ao longo de todos os horizontes que compõem os perfis, por meio de métodos analíti cos discutidos em Lacerda (1999).

A seleção dos perfis de alteração e sua amostragem foram realizadas em trabalhos de campo, observando-se, então, a correlação entre material de origem e classes de solo formado, obedecendo ao tipo de relevo estabelecido para a formação de sol os com horizonte B textural na região (declividade de 12 a 45\%). A área foi percorrida intensivamente a fim de se encontrarem perfis autóctones completos, desenvolvidos a partir de rochas frescas, com horizonte $C$ representativo das diversas fases de alteração, além de horizonte $B_{t}$ significativo.

Os perfis sel ecionados foram: Perfil 1 - Argissolo Vermelho-Amarelo distrófico (PVAd), formado a partir de rochas granitói des de composição granítica (rocha ígnea de composição ácida) do Domínio geológico intitulado Granito de Itutinga (Queméneur, 1995; Lacerda, 1999); Perfil 2 Argissolo Vermelho eutrófico (PVe), desenvolvido sobre diorito milonítico (rocha ígnea de composição intermediária) do Domínio geológico Diorito do Rosário (Queméneur, 1995; Lacerda, 1999), ePerfil 3 - Chernossolo Argilúvico férrico (MTf), tendo como material de origem um piroxenito granulitizado (rocha ígnea básica) do Domínio geológico denominado Greenstone belt de Lavras (Queméneur, 1995; Lacerda, 1999). N os três perfis selecionados, foram feitas as descrições morfológicas, as análises físicas e químicas necessárias para a correta classificação, segundo normas estabelecidas no Sistema Brasileiro de Classificação de Solos (EMBRAPA, 1999), cujos dados encontram-se em Lacerda (1999). Esses perfis apresentam as seguintes coordenadas geográficas: perfil 1 Argissolo Vermelho-Amarelo: 44035'28"W e 21017'50"S; perfil 2 - Argissolo Vermelho: 445'W e 21016'38"S, e perfil 3 - Chernossolo Argilúvico: 4502'56'W e 21011'S.

Atéo momento, a correlação regional desol os com B textural com rochas básicas e ultrabásicas (teor $\mathrm{deSiO}_{2}<45 \%$ ) era o Nitossol o Vermel ho distroférrico ou eutroférrico. No entanto, duranteas investigações de perfis dessa classe de solo, foi constatada a ocorrência inédita de Chernossol o Argilúvico férrico, que, por este motivo, foi selecionado para o estudo.

A amostragem foi realizada nas rochas e em seus diferentes estádios de alteração e nos diferentes horizontes dos solos sobre el as desenvolvidos.

Para as determinações mineralógicas, foram col etadas amostras de cerca de $0,5 \mathrm{~kg}$ de material de todos os horizontes de cada perfil. Procurou-se coletar amostras representativas desde a rocha fresca até o sól um, baseando-se em observações dos estádios de alteração, tais como: características texturais preservadas das rochas originais, composição mineralógica original, coloração, friabilidade e características morfológicas do sól um. As amostras indeformadas para a análise micromorfológica foram acondicionadas em recipientes de plástico de $10 \times 7 \mathrm{~cm}$, em substituição às caixas de Kubiena. As amostras de rocha, bem como as de solo, foram criteriosamente sel ecionadas ecol etadas, incluindo espéci mes frescos eal terados.

\section{Método de Laboratório}

As amostras de solo foram secas ao ar, destorroadas e passadas em peneiras de $2 \mathrm{~mm}$ de 
malha, sendo, então, designadas deTerra Fina Seca ao $\operatorname{Ar}$ (TFSA). As amostras indeformadas foram armazenadas em local apropriado para a secagem ao ar. As anál ises foram realizadas em laboratórios especial izados do Departamento de Ciência do Solo (DCS)/U niversidade Federal de Lavras (UFLA), do Departamento de Solos (DS)/U niversidade F ederal de Viçosa (UFV) e do Centro de Pesquisas Manoel Teixeira da Costa (CPMTC)/I nstituto de Geociências (IGC)/Universidade Federal de Minas Gerais (UFMG).

\section{Análises mineralógicas-Difração de Raios-X}

Para as análises mineralógicas, primeiramente foi feita a individualização das frações areia - silte argila a partir da TFSA. O fracionamento das amostras foi realizado por peneiragem úmida em peneira de 0,053 $\mathrm{mm}$ de malha, separando-se a fração areia. As frações silte e argila foram individualizadas por decantação e centrifugação, obedecendo à lei de Stokes.

Para a análise por difratometria de raios- $X$ da fração argila, foram confeccionadas lâminas orientadas com os seguintes materiais:

- argila desferrificada - Remoção dos óxidos de Fe pelo método DCB - ditionito-citrato-bicarbonato de sódio, segundo Mehra \& J ackson (1960);

- argila saturada com $\mathrm{K}^{+}$e $\mathrm{Mg}^{2+}$ - A saturação com $\mathrm{K}^{+}$e $\mathrm{Mg}^{2+}$ foi feita por meio de solução de $\mathrm{KCl}$ $1 \mathrm{~mol} \mathrm{~L}^{-1}$ e $\mathrm{MgCl}_{2} 1 \mathrm{~mol} \mathrm{~L}^{-1}$, respectivamente, segundo método descrito em Whittig \& Allardice (1986). As lâminas com argila saturada com $\mathrm{K}^{+}$ foram submetidas à difratometria de raios-X à temperatura ambiente $\left(25^{\circ} \mathrm{C}\right.$ ) (condição natural) e aquecidas a $550^{\circ} \mathrm{C}$. Quando necessário, foi adicionado etileno-glicol à argila saturada com $\mathrm{Mg}^{2+}$.

A análise por difratometria de raios- $X$ das amostras da fraçãoargila desferrificada foi realizada noDS/UFV, utilizando interval o de irradiação de $2 \theta$ de 5 a $50^{\circ}$, com tubo de Fe.

O restante das amostras da fração argila com os diversos tratamentos foi analisado no DCS/UFLA, utilizando intervalo de irradiação de $2 \theta$ de $5^{\circ}$ a $30^{\circ}$, com repeti ção da análise das amostras gl icol adas no intervalo de $2 \theta$ de 1 a $10^{\circ}$ e, no caso das amostras aquecidas a $550^{\circ} \mathrm{C}$, o interval o de $2 \theta$ utilizado foi de 2 a $32^{\circ}$, com tubo de Cu e filtro de $\mathrm{Ni}$.

A interpretação dos difratogramas de raios- $X$ foi realizada segundo Brown (1961), Grim (1968) eJ oint Committee on Powder Difraction Standards (1974).

\section{Análises micromorfológicas e petrográficas}

A partir das amostras indeformadas desolo, foram confeccionadas lâminas del gadas, após impregnação comaral dite. A análisemicromorfológica foi real izada em microscópio petrográfico no DCS/UFLA.

As lâminas del gadas correspondentes às rochas frescas eligeiramentealteradas foram confeccionadas nolaboratório delaminação do CPMTC/IGC/UFMG. A análise petrográfica foi realizada no DCS/UFLA.

No cálculo quantitativo dos constituintes mineralógi cos e componentes do material pedológico, utilizaram-se model os de freqüencia, estabel ecidos em campos de análise visual, individualizados durante a análise mi croscópica, de acordo com vários autores, particularmenteBullock et al. (1985).

\section{Análises geoquímicas}

As amostras de rocha fresca correspondentes ao material deorigem dos perfis foram geoqui micamente caracterizadas por meio de métodos combinados de Fluorescência de Raios-X (FRX) eEspectroscopia de Emissão Atômica com Plasma de Acoplamento Indutivo (ICP) no CPMTC/IGC/UFMG.

\section{RESULTADOS}

\section{Caracterização e classificação dos perfis}

Para a classificação dos perfis sel ecionados para o estudo, segundo normas estabel ecidas no Sistema Brasileiro de Classificação de Solos (EMBRAPA, 1999), foram realizadas as descrições morfológicas eas análises físicas e quími cas necessárias, aolongo de todos os horizontes que constituem os perfis, de acordo com métodos discutidos em Lacerda (1999). Os principais atributos, particularmente para caracterização do horizonte diagnóstico B textural, encontram-se sumariados no quadro 1.

\section{Mineralogia da fração argila}

Noperfil 1- Argissol oVermelho-Amarelodistrófico, a mineralogia da fração argila ao longo do perfil de alteração foi caracterizada em: horizontes $C_{2}, C_{1}, B C$ e $\mathrm{B}_{\mathrm{t}}$ : caulinita, gibbsita e illita; e horizonte $\mathrm{A}$ : caulinita e gibbsita.

No perfil 2 - Argissolo Vermel ho eutrófico, a mineralogia da fração argila caracterizada ao longo do perfil de alteração foi a seguinte: horizontes $C_{3}$, $\mathrm{C}_{2}$ e $\mathrm{C}_{1}$ : caulinita, illita e vermiculita com hidróxi nas entrecamadas; horizonte BC: caulinita, illita, vermiculita com hidróxi nas entrecamadas e gibbsita; e horizontes $\mathrm{B}_{\mathrm{t}}$ e $\mathrm{A}$ : caulinita, gibbsita e vermiculita com hidróxi nas entrecamadas.

J á no perfil 3- Chernossolo Argilúvico férrico, a mineral ogia da fração argila foi assim caracterizada: horizontes $C_{3}, C_{2}, C_{1}, B C, B_{t}$ e A: caulinita, talco e esmectita.

\section{Caracterização geoquímica do material de origem dos perfis de alteração}

O quadro 2 apresenta a composição geoquímica dos materiais de origem dos perfis sel ecionados para 
Quadro 1. Características morfológicas e analíticas dos perfis 1, 2 e 3

\begin{tabular}{|c|c|c|c|c|c|c|c|c|c|c|c|}
\hline \multirow{2}{*}{ Horizonte } & \multicolumn{5}{|c|}{ Característica morfológica } & \multicolumn{6}{|c|}{ Característica analítica } \\
\hline & Cor & Cerosidade & Estrutura & Textura & Espessura & $\mathbf{B} / \mathbf{A}$ & $\begin{array}{l}\text { Silte/ } \\
\text { argila }\end{array}$ & $\mathbf{v}$ & $\mathbf{T}_{\text {argila }}$ & c & $\mathrm{Fe}_{2} \mathrm{O}_{3}(\mathbf{l})$ \\
\hline & & & & & $\mathrm{cm}$ & & & $\%$ & $\mathrm{cmol}_{\mathrm{C}} \mathrm{dm}^{-3}$ & $\mathrm{~g} \mathrm{~kg}^{-1}$ & dag $\mathrm{kg}^{-1}$ \\
\hline \multicolumn{12}{|c|}{ Perfil 1 - Argissolo Vermelho-Amarelo distrófico } \\
\hline A & $5 Y R 4 / 2$ & - & $\begin{array}{l}\text { mod. gr./mod.fr. } \\
\text { b. ang. }\end{array}$ & média & 55 & 1,17 & 1,78 & 13 & 36 & 11 & 2,0 \\
\hline B & $5 Y R / 5 / 8$ & $\begin{array}{l}\text { mod. e } \\
\text { comum }\end{array}$ & $\begin{array}{l}\text { mod. b. } \\
\text { ang./subang. }\end{array}$ & média & 40 & & 1,09 & 13 & 22 & 4 & 2,0 \\
\hline \multicolumn{12}{|c|}{ Perfil 2 - Argissolo Vermelho eutrófico } \\
\hline A & $5 Y R 4 / 6$ & - & $\begin{array}{l}\text { mod. gr./mod. } \\
\text { b. ang. }\end{array}$ & média & 20 & 1,2 & 1,34 & 65 & 34 & 18 & 8,1 \\
\hline B & $2,5 Y R 4 / 8$ & $\begin{array}{l}\text { forte e } \\
\text { abundante }\end{array}$ & f. b. ang./subang. & $\begin{array}{l}\text { média a } \\
\text { argilosa }\end{array}$ & 60 & & 1,22 & 65 & 17 & 5 & 10,0 \\
\hline \multicolumn{12}{|c|}{ Perfil 3 - Chernossolo Argilúvico férrico } \\
\hline A & $5 Y R 3 / 3$ & - & mod.gr fr. b. ang. & média & 18 & 3,25 & 2,25 & 79 & 106 & 21 & 14,5 \\
\hline B & $2,5 Y R 3 / 6$ & $\begin{array}{l}\text { forte e } \\
\text { abundante }\end{array}$ & f. b. ang./subang. & argilosa & 37 & & 0,65 & 87 & 37 & 6 & 21,3 \\
\hline
\end{tabular}

(1) extraído pelo ataque sulfúrico, mod. =moderada, f. =forte, fr. =fraca, gr. =granular, b. =blocos, ang. =angulares, subang. = subangulares, B/A = relação textural de argila entre os horizontes B e A, V = saturação por bases da CTC a pH 7, T argila $=$ atividade (CTC) da argila, C = carbono orgânico.

Quadro 2. Composição geoquímica das rochas de origem dos perfis de alteração

\begin{tabular}{|c|c|c|c|c|c|c|c|c|c|c|c|c|}
\hline \multirow[b]{2}{*}{ Perfil } & \multicolumn{12}{|c|}{ Elemento maior - óxido constituinte } \\
\hline & $\mathrm{SiO}_{2}$ & $\mathrm{Al}_{2} \mathrm{O}_{3}$ & $\mathrm{Fe}_{2} \mathrm{O}_{3}$ & $\mathrm{CaO}$ & MgO & $\mathrm{Na}_{2} \mathrm{O}$ & $\mathrm{K}_{2} \mathrm{O}$ & $\mathrm{TiO}_{2}$ & Mno & $\mathbf{P}_{2} \mathrm{O}_{5}$ & $\mathbf{P F}$ & Total \\
\hline & & & & & & dag & & & & & & - \\
\hline 1 & 72,10 & 14,38 & 1,57 & 0,92 & 0,24 & 4,25 & 5,63 & 0,12 & $<0,01$ & 0,03 & 0,76 & 100,0 \\
\hline 2 & 55,64 & 17,10 & 7,54 & 6,68 & 3,80 & 5,22 & 1,20 & 0,94 & 0,08 & 0,23 & 1,58 & 100,0 \\
\hline 3 & 52,12 & 9,08 & 11,58 & 10,90 & 11,80 & 2,89 & 0,09 & 0,73 & 0,17 & 0,05 & 0,60 & 100,0 \\
\hline
\end{tabular}

(1) PVAd = Argissolo Vermelho-Amarelo distrófico: Granito. ${ }^{(2)}$ PVe = Argissolo Vermelho eutrófico: Diorito milonítico. ${ }^{(3)}$ MTf = Chernossolo Argilúvico férrico: Piroxenito granulitizado.

o estudo, corroborando a classificação de domínios geológicos de composição ácida, intermediária e básica. O perfil 1 (PVAd) éformado a partir de rochas granitóides de composição granítica (rocha ígnea de composição ácida) do Domínio geológico intitulado Granito de Itutinga (Queméneur, 1995; Lacerda, 1999); o perfil 2 (PVe) desenvolve-se sobre diorito milonítico (rocha ígnea decomposição intermediária) do Domínio geológico Diorito do Rosário (Queméneur, 1995; Lacerda, 1999), eo perfil 3 (MTf) tem como material de origem um piroxenito granulitizado (rocha ígnea básica) do Domínio geológico denominado Greenstone-belt de Lavras (Queméneur, 1995; Lacerda, 1999).

\section{Petrografia e micromorfologia dos perfis de alteração}

A descrição microscópica dos perfis 1, 2 e 3, individualizada em caracterização petrográfica dos fácies rocha fresca de origem e descrição micromorfológica doalterito (horizontes $C$ ), fácies de transição (horizonte BC) efácies sólum (horizonte Bt 
e A), encontra-se sumariada nos quadros 3, 4 e 5. Microfotografias ao longo dos perfis, desde a rocha fresca até o sólum (Figuras 1, 2 e 3), ilustram a evolução do processo pedogenético dos solos.

\section{DISCUSSÃO}

A evolução dos perfis de alteração mostrou-se diretamente vinculada à textura, composição química e mineralógica dos materiais originais, refletindo-se nas características micromorfológicas e composição mineralógica dos horizontes que compõem cada perfil, especialmente o horizonte diagnóstico - B textural, que, por sua vez, vão refletir nos seus atributos físicos e químicos, avaliados por Lacerda (1999). A caracterização micromorfológica encontra-se, também, coerente com a avaliação do comportamento geoquímico do processo deal teração realizado ao longo da seqüência de evolução pedogenética desses perfis, de acordo com resultados discutidos em Lacerda (1999).
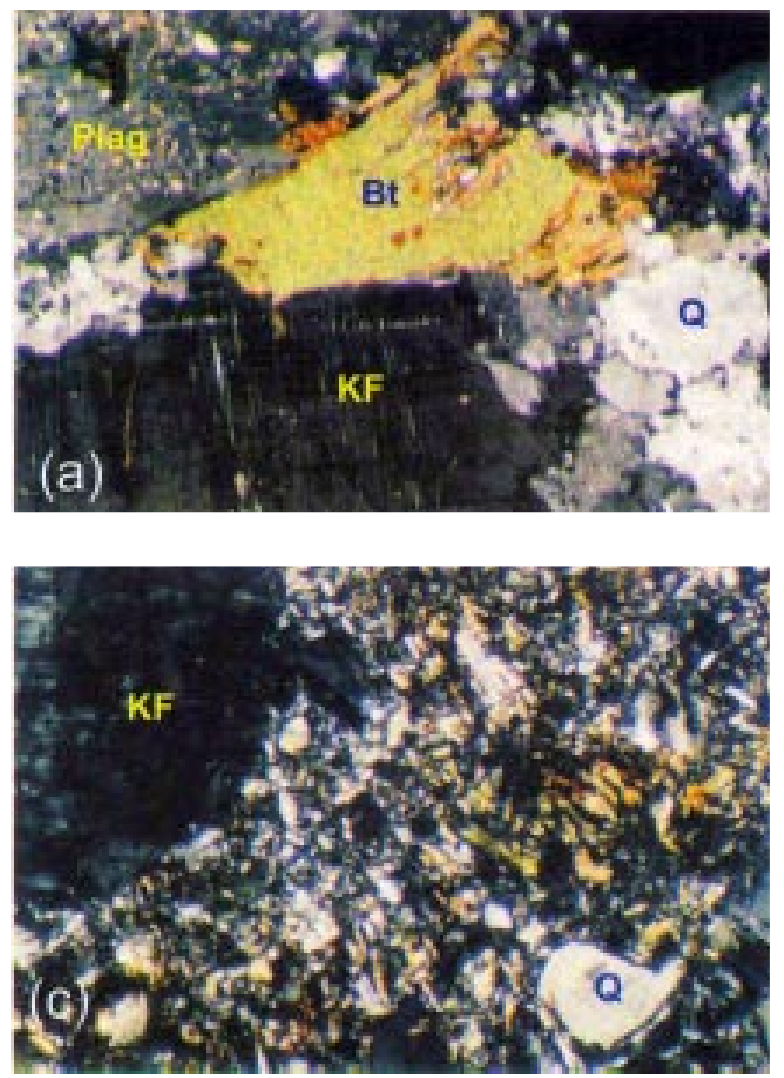

\section{Perfil 1-Argissolo Vermelho-Amarelo distrófico}

Este perfil tem como material de origem um granito, rocha de composição ácida (Quadro 2), com constituição mineralógica e características texturais apresentadas na descrição petrográfica do quadro 3. A mineralogia essencial é representada, segundo Goldich (1938), citado por Besoain (1985), por minerais de grau de intemperização lento (quartzo, feldspato potássico e moscovita/sericita), minerais de grau de intemperização moderado (plagioclásio sódico-cálcico) e, no caso analisado, menos de $10 \%$ de minerais de intemperização rápida (anfibólio: hornblenda-edenita, biotita, epidoto, carbonato e clorita) (Quadro 3 eFigura 1a). E uma rocha debaixo teor em ferro (Quadro 2), presente na composição do anfibólio, biotita eclorita, além de minerais opacos (óxidos de ferro), que constituem traços na rocha em questão.

As características micromorfológicas deste perfil de alteração, cuja descrição encontra-se individualizada em fácies alterito (horizontes $\mathrm{C}_{2}$ e $\mathrm{C}_{1}$ ), fácies de transição (horizonte BC) e fácies sólum

Figura 1. Microfotografias ao longo do perfil 1 - Argissolo Vermelho-Amarelo. (a) Fácies rocha fresca ( $K F$ = feldspato potássico, Plag = plagioclásio, Bt =biotita e Q =quartzo); (b) Fácies alterito - horizonte $\mathrm{C}_{3}$ (PlagA = plagioclásio argilizado); (c) Fácies de transição-horizonte BC, evolução dos processos de argilização; (d) Fácies sólum-horizonte Bt (Q = quartzo - esqueleto, P = plasma, CRAM = cristais relictuais à alteração mineralógica). (Obj 6.3x; Oc 8x). 
(horizontes $B_{t}$ e $A$ ), apresentadas no quadro 3 , mostram quea composição mineralógica do material original reflete-se em sua evolução pedogenética. A alteração é fraca a moderada no alterito, não apresentando evolução significativa em direção ao sólum (Figura 1b, c e d). O alterito, assim como o horizonte $\mathrm{B}_{\mathrm{t}}$, apresenta cerca de $40-45 \%$ de esqueleto, com predomínio do quartzo e feldspato potássico, além da presença dos demais minerais silicatados primários(5), com exceção do anfibólio, que desaparece nos primeiros estádios de alteração (Quadro 3). O plagioclásio sofrerápida argilização na fase inicial da alteração (Figura 1b). O plasma apresenta praticamente a mesma distribuição relativa, tanto no al terito como no horizonte $B_{t}$ (cerca de 57\%), constituído pela associação caulinita, gibbsita eillita (cerca de 30\%) esesquióxidos deferro(hematita/ goethita), variando de 2 a 13\% do al terito ao sólum.

\section{Quadro 3. Descrição microscópica do perfil 1 - Argissolo Vermelho-Amarelo distrófico}

\begin{tabular}{|c|c|c|c|}
\hline \multicolumn{4}{|c|}{ Descrição petrográfica } \\
\hline Característica & Fácies Rocha Fresca: Granito & \multicolumn{2}{|c|}{ Fácies Rocha Alterada } \\
\hline Mineralogia essencial & $\begin{array}{l}\text { KF (30\%), Plag (35\%), Q (25\%), } \\
\text { Bt e HE (5\%) }\end{array}$ & \multicolumn{2}{|c|}{ KF (30\%), Plag (35\%), Q (25\%), Bt e HE (5\%) } \\
\hline Mineralogia secundária(1) & Bt - Ep - M/St - Cb - Tit - Op (5\%) & \multicolumn{2}{|c|}{$\mathrm{Bt}-\mathrm{Ep}-\mathrm{M} / \mathrm{St}-\mathrm{Cb}-\mathrm{Tit}-\mathrm{SFe}$ - Argilo-mineral (5\%) } \\
\hline Mineralogia acessória & Zr, Allanita & \multicolumn{2}{|l|}{ Zr, Allanita } \\
\hline Textura & $\begin{array}{l}\text { Granoblástica, xenomórfica } \\
\text { a hipidiomórfica }\end{array}$ & \multicolumn{2}{|l|}{$\begin{array}{l}\text { Fraturamento cristalino } \\
\text { e corrosão de borda cristalina }\end{array}$} \\
\hline \multicolumn{4}{|c|}{ Descrição micromorfológica } \\
\hline Característica & Fácies alterito $\left(C_{2}\right.$ e $\left.C_{1}\right)$ & Fácies de transição (BC) & Fácies Sólum ( $B_{t}$ e A) \\
\hline E squeleto (\%) & 40 a $45 \%$ & $40 \%$ & $40 \%$ \\
\hline Constituição mineralógica & $\begin{array}{l}\mathrm{Q}(20-28 \%), K F(15-18 \%) \\
\mathrm{Bt}-\mathrm{Ep}-\mathrm{Cl}-\mathrm{M}-\mathrm{Op}(2-5 \%)\end{array}$ & $\begin{array}{l}\mathrm{Q}(23 \%), \mathrm{KF}(15 \%) \\
\mathrm{Bt}-\mathrm{M}-\mathrm{Op}(<2 \%)\end{array}$ & Q (28\%), KF (10\%), Bt - M - Op (2\%) \\
\hline Dimensões (max, min, média) & $4,00,0,04$ e $0,40 \mathrm{~mm}$ & $0,80,0,04$ e $0,40 \mathrm{~mm}$ & $0,80,0,04$ e $0,40 \mathrm{~mm}$ \\
\hline Origem & “in situ”(2) & “in situ” & "in situ” \\
\hline Textura superficial & $\begin{array}{l}\text { Normal (Q), corroída e fraturada } \\
\text { (KF), discretamente ferruginizada } \\
\text { (demais) }\end{array}$ & $\begin{array}{l}\text { Corroída e fraturada (Q e KF), } \\
\text { discretamente ferruginizada } \\
\text { (demais) }\end{array}$ & $\begin{array}{l}\text { Corroída e fraturada ( Q e KF), } \\
\text { discretamente ferruginizada (demais) }\end{array}$ \\
\hline Distribuição de base(3) & Agrupada & Aleatória & Aleatória \\
\hline Plasma (\%) & 55 a $60 \%$ & $57 \%$ & $57 \%$ \\
\hline Constituição mineralógica & $\begin{array}{l}\mathrm{Ct}-\mathrm{Gb}-\text { It }(30-38 \%), \mathrm{SFe} \text { (2-5\%), } \\
\text { CRAM (St - Bt - M - Ep) (15-20\%) }\end{array}$ & $\begin{array}{l}\text { Ct - Gb - It (30\%), SFe (12\%), } \\
\text { CRAM (St - Bt e M) (15\%) }\end{array}$ & $\begin{array}{l}\text { Ct - Gb - (It) (29\%), SFe (13\%), } \\
\text { CRAM (St - Bt e M) (15\%) }\end{array}$ \\
\hline Estrutura plásmica(3) & Crística & Omnissépica a bimassépica & Omnissépica a bimassépica \\
\hline Distribuição relativa(3) & Porfírica composta & Porfírica fechada a quitônica & Porfírica fechada \\
\hline Vazios (\%) & $<1 \%$ & $3 \%$ & $3-10 \%$ \\
\hline Formas/tipos ${ }^{(4)}$ & Ortocavidades & Ortocavidades & $\begin{array}{l}\text { Ortocavidades, intergranulares } \\
\text { complexos, cavidades e canais }\end{array}$ \\
\hline Origem & Litopórica (“box works”) & Litopórica (“box works”) & Pedopórica e litopórica \\
\hline Dimensões & Máximas: 1,00 mm & Máximas: 3,20 mm & Máximas: 2,80 mm \\
\hline Feições pedológicas (\%) & Ausentes & Ausentes & Presentes \\
\hline $\operatorname{Tipos}^{(5)}$ & & & Pedotúbulos \\
\hline Processos pedogenéticos & $\begin{array}{l}\text { Lixiviação (“box works”), } \\
\text { Pseudomorfose, Ferruginização } \\
\text { incipiente, Argilização } \\
\text { (bissialitização, monossialitização } \\
\text { e alitização) }\end{array}$ & $\begin{array}{l}\text { Lixiviação ("box works”), } \\
\text { Pseudomorfose, F erruginização } \\
\text { fraca, Argilizaçãã (bissialitização, } \\
\text { monossialitização e alitização) }\end{array}$ & $\begin{array}{l}\text { Lixiviação ("box works"), } \\
\text { Pseudomorfose, Ferruginização fraca, } \\
\text { Argilização (bissialitização, } \\
\text { monossialitizaçãa e al itização) }\end{array}$ \\
\hline Grau de pedalidade & Muito fraco & Fraco & Fraco \\
\hline
\end{tabular}

(1) Decorrente de reações mineralógicas retrógradas (hidrotermais ou retrometamórficas). ${ }^{(2)}$ Decorrente de substituições mineralógicas retrógradas. (3) Segundo Stoops e J ongerius (1975). (4) Segundo Brewer (1964) e Pettijohn (1949). (5) Segundo Bullock et al. (1985). Plag = Plagioclásio; HE = Hornblenda-E denita; Q =Q Quartzo; KF =Feldspato potássico; $\mathrm{Ep}=\mathrm{E}$ pidoto; $\mathrm{Bt}=\mathrm{Biotita;} \mathrm{M}=\mathrm{M}$ oscovita; St =Sericita; $\mathrm{Cl}=$ =Clorita; $\mathrm{Cb}=$ Carbonato; $\mathrm{Zr}=$ Zirconita; Op =Opacos; It =Illita; Ct =Caulinita; Gb =Gibbsita; SFe =Sesquióxidos de Fe; CRAM = Cristais relictuais à alteração mineralógica.

(5) Primários referem-se a minerais primários à alteração intempérica, muitas vezes não sendo minerais primários da rocha de origem. 

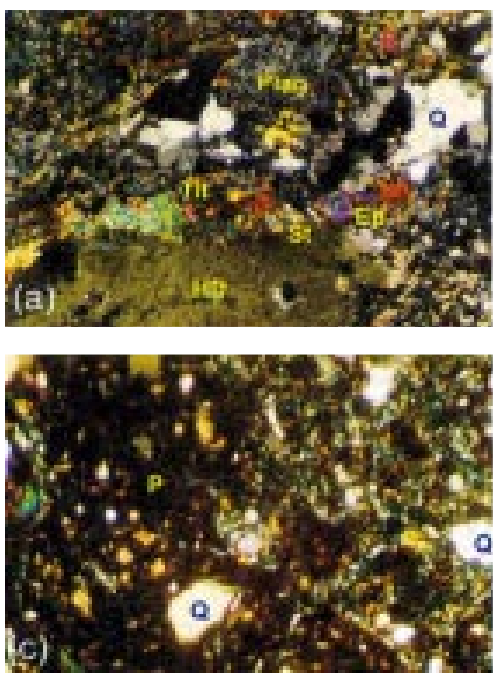
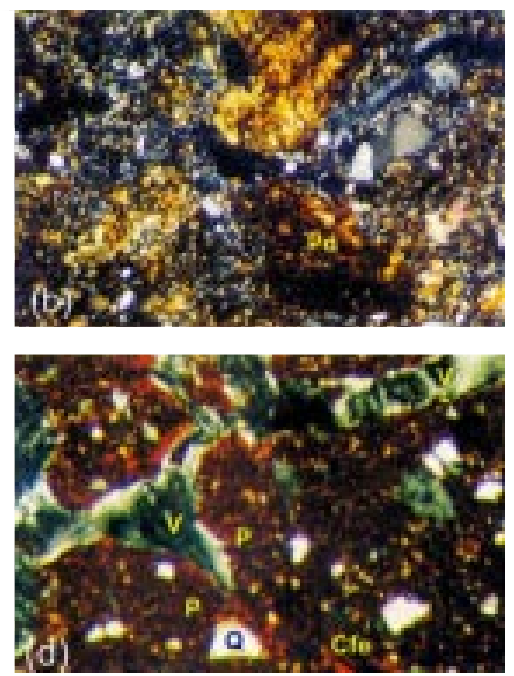

Figura 2. Microfotografias ao longo do perfil 2-Argissolo Vermel ho. (a) Fácies rocha fresca (HD =hornblendaedenita; Plag = plagioclásio, Q =quartzo, E p =epidoto, St =sericita e Tit =titanita); (b) Fácies alteritohorizonte $\mathrm{C}_{3}$ ( $\mathrm{Pd}=$ pseudomorfos de HD, processos de argilização e ferruginização); (c) Fácies de transição-horizonte BC, evolução dos processos de argilização eferruginização (Q = quartzo, $\mathbf{P}=$ plasma); (d) Fácies sólum-horizonte Bt ( $Q$ = quartzo - esqueleto, $\mathbf{V}$ =vazios, $\mathbf{P}=$ plasma a argilominerais silicatados + sesquióxidos de Fe e Al, Cfe =cutans - ferriargilans, indicativo de processo de iluviação). (Obj 6.3x; Oc 8x).
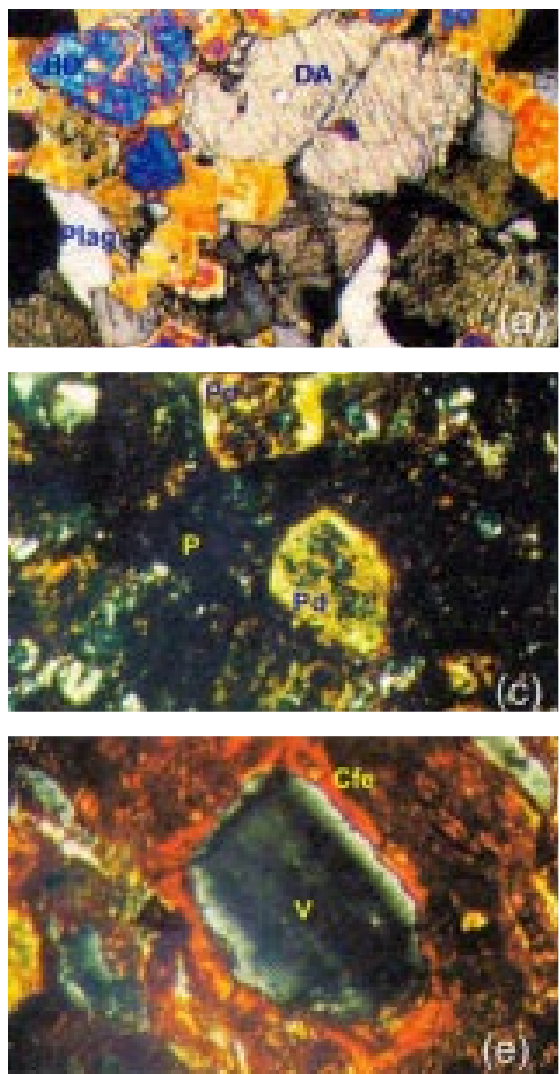
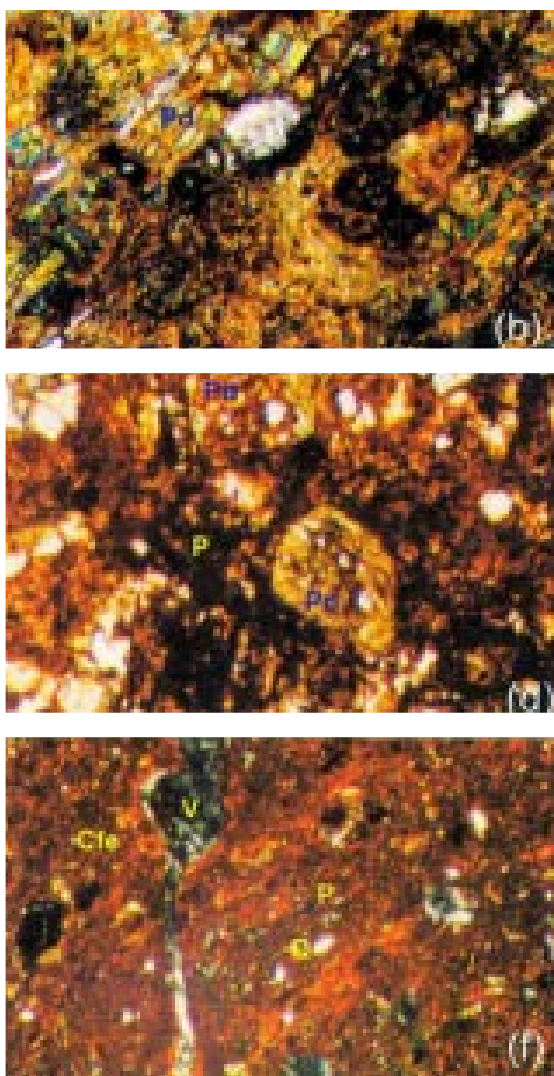

Figura 3. Microfotografias ao longo do perfil 3 - Chernossolo Argilúvico. (a) Fácies rocha fresca (DA = diopsídio-augita, HD = hornblenda-edenita, Plag = plagioclásio); (b) Fácies alterito-horizonte $C_{2}$ (Pd = pseudomorfos de DA e HD, processos de argilização e ferruginização); (c) Fácies de transição - horizonte BC (Pd =pseudomorfos de DA e HD, evolução dos processos de argi lização e ferruginização) em ni cóis cruzados; (d) Idem (c) em nicóis paralelos; (e) Fácies de transição-horizonte BC (V = vazioslitoporos, Cfe =cutans - ferriargilans e ferrans indicativos de processo de iluviação); (f) Fácies sólum - horizonte Bt ( $Q$ =quartzo- esqueleto, $\mathbf{V}=$ vazios, $\mathbf{P}=$ plasma a argilominerais silicatados +sesquióxidos de $\mathrm{Fe}, \mathrm{Cfe}=$ cutans - ferriargi lans e ferrans, indicativos de processo de iluviação). (Obj 6.3x; Oc 8x). 
Outros minerais primários microcristalinos, além da sericita, mostram-se presentes no plasma do horizonte $B_{t}$, evidenciando pouca evolução no processo de alteração (Quadro 3 e Figura 1d). Tal evolução é governada pelo baixo grau de intemperização da mai oria dos minerais silicatados do material originário, formando um sólum de textura geralmente arenosa, dada a tendência de concentração desses minerais no esquel eto, principalmente o quartzo e o feldspato potássico, além da moscovita. Apesar da grande proporção de esqueleto, a distribuição relativa permanece porfírica, com tendência a quitônica (Quadro 3). Essa evolução revela hidról ise sel etiva em rel ação ao grau de intemperização dos minerais, que, no entanto, quando atuante, atinge a alitização (dessilicatização completa, com formação de gibbsita) já no alterito, marcada pela presença de gibbsita. A liberação de ferro, assim como o processo de ferruginização, é compatível com a pequena quantidade desse el emento na composição mineralógica da rocha original.

Os processos de lixiviação e pseudomorfose são, então, moderados a fracos. A presença de box works ${ }^{(6)}$ é limitada, não colaborando no desenvol vimento de litoporos, e os vazios não ultrapassam 3-10\% no horizonte $\mathrm{B}_{\mathrm{t}}$ (Quadro 3), que mostra grau de pedalidade fraco.

A análise da substituição mineralógica ao longo do perfil permitiu estabelecer a seguinte ordem de destruição intempérica dos minerais silicatados primários ao longo do perfil de alteração: Anfibólio (Hornblenda-Edenita) - Carbonato - Plagioclásio Titanita - Epidoto/Clorita/Biotita - Moscovita Sericita - Feldspato potássico. Estes resultados encontram-se coerentes com trabalhos afins realizados por diversos autores, tais como Cerri (1979) e Menegotto \& Gaspareto (1987).

\section{Perfil 2 - Argissolo Vermelho eutrófico}

O diorito milonítico - material de origem deste perfil - é uma rocha de composição intermediária, cuja composição geoquímica acha-se apresentada no quadro 2 e a descrição petrográfica no quadro 4 . É constituído por minerais silicatados de intemperização rápida a moderada, al guns portadores de Fe e Mg na sua composição química (anfibólio: hornblenda-edenita, biotita e clorita), outros portadores de $\mathrm{Ca}$ (plagioclásio, epidoto e titanita) (Goldich, 1938, citado por Besoain, 1985). O FeeTi também estão presentes em óxidos deferro etitânito (magnetita e ilmenita), estando representados no quadro 4 como minerais opacos. Entre os minerais resistentes ao intemperismo, destaca-se a ocorrência moderada a discreta de quartzo (Quadro 4 e Figura 2a).
A caracterização microscópica dessa rocha (Quadro 4) mostra que sua alteração ao longo do perfil é de moderada a acentuada desde o alterito (Figura 2b e c), evoluindo em direção ao sólum, atingindo clímax no horizonte $B_{t}$, onde se observam diminuição da proporção de esqueleto (de 25 para 15\%) e acréscimo discreto do plasma (de 65 para $70 \%$, passando o esquel eto a ser constituído basicamente por quartzo, desaparecendo os demais minerais primários (Quadro 4 e Figura 2d).

No plasma do sólum, mais significativo que a abundância relativa éa sua composição mineral ógica, representada por associação de caulinita, gi bbsita e vermiculita com hidróxi nas entrecamadas, do qual $30 \%$ éconstituído de sesquióxidos de ferro (hematita/ goethita) e titânio, desaparecendo os demais minerais silicatados primários. Desta maneira, a estrutura plásmica crística no alterito (Quadro 4 e Figura 2b) passa a omnissépica no sólum, com distribuição relativa porfírica (Quadro 4 e Figura 2d). I sso demonstra a atuação de hidrólise crescente dos minerais aluminossilicatados primários, que se inicia com a bissialitização (dessilicatização limitada, com formação de argil ominerais 2:1 - vermiculita) e monossialitização (dessilicatização moderada, com formação de argilominerais 1:1 - caulinita) no alterito, evoluindo para alitização (dessilicatização completa, com formação de gibbsita) no sólum, com liberação de $\mathrm{Fe}$, entre outros cátions, promovendo o processo de ferruginização crescente.

Essa evoluçãoér eflexo da composiçãomineralógica e química da rocha originária, restando do processo de alteração somente o quartzo, mineral resistente ao intemperismo, cuja tendência é concentração na fração mais grosseira do solo, constituindo o esquel eto. Os demais mi nerais silicatados primários foram substituídos por mineralogia secundária de origem intempérica, basicamente argilominerais silicatados e sesquióxidos de alumínio e ferro.

Assim sendo, processos de lixiviação e pseudomorfose variam de moderados a acentuados. A ocorrência de box works reflete-se no acréscimo de vazios, especialmente no sólum, favorecendo o desenvolvimento da pedalidade, atingindo grau moderado a forte. A presença de ferriargilans de grãos, poros eagregados (Quadro 4 eFigura 2d) pode evidenciar processo de iluviação, concordando com os atributos diagnósticos do horizonte B textural, descritos em Lacerda (1999).

A análise da substituição mineralógica ao longo do perfil permitiu estabelecer a seguinte ordem de destruição intempérica dos minerais silicatados primários ao longo do processo dealteração: Anfibólio (Hornblenda-Edenita) - Plagioclásio - Titanita Clorita/E pidoto/Biotita - Sericita.

(6) box works referem-se a espaços vazios decorrentes da lixiviação de minerais, cuja forma ainda se mantém preservada. 


\section{Quadro 4. Descrição microscópica do perfil 2 - Argissolo Vermelho eutrófico}

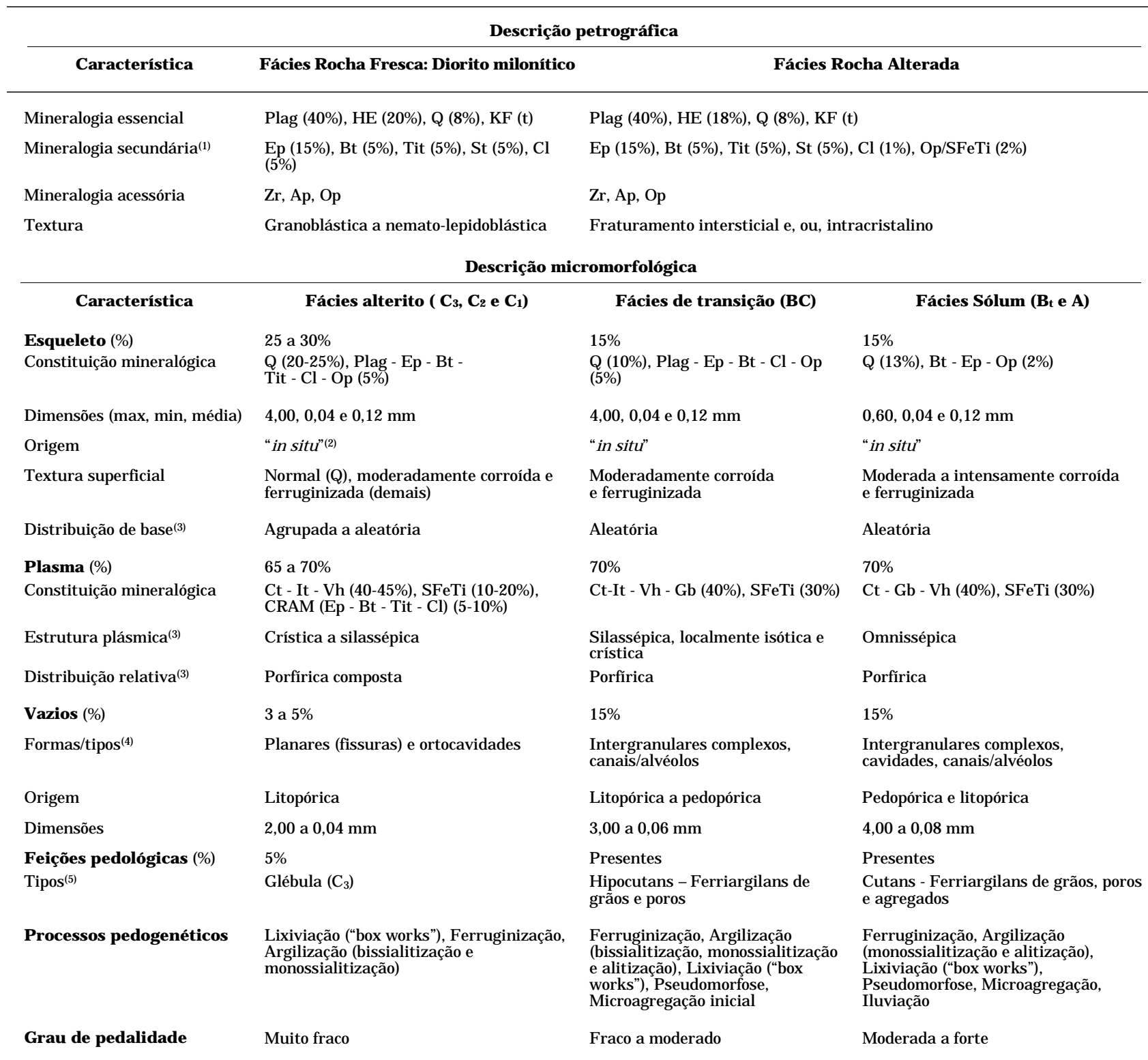

(1) Decorrente de reações mineralógicas retrógradas (hidrotermais ou retrometamórficas). ${ }^{(2)}$ Decorrente de substituições mineralógicas retrógradas. (3) Segundo Stoops \& J ongerius (1975). (4) Segundo Brewer (1964) e Pettijohn (1949). (5) Segundo Bullock et al. (1985). Plag =Plagioclásio; HE =Hornblenda-Edenita; Q =Quartzo; KF =Feldspato potássico; Ep =E pidoto; Bt =Biotita; Tit =Titanita; St =Sericita; $\mathrm{Cl}=$ Clorita; $\mathrm{Zr}=$ Zirconita; $\mathrm{Ap}=$ Apatita; $\mathrm{Op}=$ Opacos; It =Illita; $\mathrm{Ct}=$ Caulinita; Vh =Vermiculita com hidróxi nas entrecamadas; $\mathrm{Gb}=$ Gibbsita; SFeTi =Sesquióxidos de Fe e Ti; CRAM =Cristais relictuais à alteração mineralógica; $\mathrm{t}=$ traços.

\section{Perfil 3 - Chernossolo Argilúvico férrico}

A rocha de origem do perfil 3 é um piroxenito granulitizado, conforme descrição petrográfica apresentada no quadro 5, rocha de composição básica (Quadro 2), constituída, segundo Goldich (1938), citado por Besoain (1985), por minerais essenciais de rápi da meteorização, apresentando Fee Mg na sua composição química (clinopiroxênio: diopsídio-augita, anfibólio: hornblenda-edenita e tremolita-actinolita), além do plagioclásio, que contém Ca e Na na sua composição (Figura 3a). O Fee Ti também estão presentes em sesquióxidos de ferro e titânio.

Esta composi ção mineralógica éresponsável pela rápida evolução da alteração dos minerais primários do alterito atéo sól um (Quadro 5). O al terito mostrase constituído por $40 \%$ até $60 \%$ de esqueleto, representado pela maioria dos minerais primários, 
com exceção do clinopiroxênio (diopsídio-augita) e eventualmente anfibólio (hornblenda-edenita), que já sofreram pseudomorfose neste estádio de intemperização (Figuras 3b, c e d). O plasma (35 a $55 \%)$ é representado pela associação caulinita, talco e esmectita (20 a 25\%) e sesquióxidos de ferro (hematita/goethita) (10 a 30\%), além de tremolitaactinolita/uralita e sericita (até $5 \%$ ). No sólum, o esquel eto contribui somente com $12 \%$ (Quadro 5 e
Figura 3f), sendo $5 \%$ de pseudomorfos de clinopiroxênio e anfibólio, e o plasma passa a constituir $70 \%$ da abundância relativa, não apresentando minerais primários suceptíveis à intemperização (35\% da associação caulinita, talco e esmectita e $35 \%$ de sesquióxidos deferro(hematita/ goethita)). Os vazios sofrem acréscimo de $5 \%$ no alterito para $18 \%$ no horizonte $B_{t}$ (Quadro 5 e Figura 3f).

\section{Quadro 5. Descrição microscópica do perfil 3 - Chernossolo Argiluvico férrico}

\begin{tabular}{|c|c|c|c|c|}
\hline \multicolumn{5}{|c|}{ Descrição petrográfica } \\
\hline Característica & \multicolumn{2}{|c|}{ Fácies Rocha Fresca: Piroxenito granulitizado } & \multicolumn{2}{|c|}{ Fácies Rocha Alterada } \\
\hline $\begin{array}{l}\text { Mineralogia essencial } \\
\text { Mineralogia secundária } \\
\text { Mineralogia acessória } \\
\text { Textura }\end{array}$ & $\begin{array}{l}\text { DA (30\%), HE (30\%), Plag (35 } \\
\text { TA/U - St - SFeTi (5\%) } \\
\text { Apatita } \\
\text { Nematoblástica }\end{array}$ & \%), Q (t) & $\begin{array}{l}\text { DA (30\%), HE (35\%), Plag ( } 25 \%) \\
\text { TA/U - St - SF eTi - Argilo-miner } \\
\text { Apatita } \\
\text { Fraturamento intersticial e, ou, }\end{array}$ & $\begin{array}{l}\text { Q (t) } \\
\text { al (10\%) } \\
\text { intracristalino }\end{array}$ \\
\hline \multicolumn{5}{|c|}{ Descrição micromorfológica } \\
\hline Característica & Fácies Alterito $\left(C_{3}, C_{2}\right)$ & Fácies Alterito $\left(C_{1}\right)$ & Fácies de Transição (BC) & Fácies Sólum ( $B_{t}$ e A) \\
\hline Esqueleto (\%) & $60 \%$ & $40 \%$ & $30 \%$ & $12 \%$ \\
\hline Constituição mineralógica & $\begin{array}{l}\text { HE (30\%), PDA (10\%), Plag } \\
(15 \%), \text { Op (5\%), Q (t) }\end{array}$ & $\begin{array}{l}\text { PHE/DA (25\%), Plag (10\%), } \\
\text { Op (2\%) }\end{array}$ & $\begin{array}{l}\text { PHE/DA (25\%), Plag (2\%), Op } \\
(3 \%)\end{array}$ & $\begin{array}{l}\text { PHE/DA (5\%), PPlag (t), Op } \\
(2 \%), \text { Q (5\%) }\end{array}$ \\
\hline $\begin{array}{l}\text { Dimensões } \\
\text { (max, min, média) }\end{array}$ & \multicolumn{2}{|c|}{$2,00 \mathrm{~mm}, 0,04 \mathrm{~mm}, 0,40 \mathrm{~mm}$} & $2,00 \mathrm{~mm}, 0,04 \mathrm{~mm}, 0,40 \mathrm{~mm}$ & $0,52 \mathrm{~mm}, 0,04 \mathrm{~mm}, 0,20 \mathrm{~mm}$ \\
\hline Origem & \multicolumn{2}{|c|}{ "in situ”" } & “in situ” & “in situ” \\
\hline Textura superficial & \multicolumn{2}{|c|}{ Corroída, fraturada e ferruginizada } & $\begin{array}{l}\text { Corroída, fraturada e } \\
\text { ferruginizada }\end{array}$ & $\begin{array}{l}\text { Corroída, fraturada e } \\
\text { ferruginizada }\end{array}$ \\
\hline Distribuição de base ${ }^{3}$ & Agregada & Aleatória & Aleatória & Aleatória \\
\hline Plasma (\%) & $35 \%$ & $55 \%$ & $55 \%$ & $70 \%$ \\
\hline Constituição mineralógica & $\begin{array}{l}\text { Ct - Tc - Et (20\%), SFeTi } \\
(10 \%), \text { CRAM (TA/U - St ) } \\
(5 \%)\end{array}$ & $\begin{array}{l}\text { Ct - Tc - Et (25\%), SFeTi } \\
(30 \%)\end{array}$ & $\begin{array}{l}\text { Ct - Tc - Et (25\%), SFeTi } \\
(30 \%)\end{array}$ & $\begin{array}{l}\text { Ct -Tc - Et (35\%), SFeTi } \\
(35 \%)\end{array}$ \\
\hline Estrutura plásmica & Crística & Omnissépica & $\begin{array}{l}\text { Omnissépica a isotrópica } \\
\text { isótica }\end{array}$ & $\begin{array}{l}\text { Omnissépica a isotrópica } \\
\text { isótica }\end{array}$ \\
\hline Distribuição relativa(3) & Quitônica & Porfírica fechada & Porfírica & Porfírica aberta \\
\hline Vazios (\%) & $5 \%$ & $5 \%$ & $15 \%$ & $18 \%$ \\
\hline Formas/tipos(4) & $\begin{array}{l}\text { Planares (fissuras) e } \\
\text { ortocavidades }\end{array}$ & $\begin{array}{l}\text { Cavidades, canais e } \\
\text { intergranulares complexos }\end{array}$ & $\begin{array}{l}\text { Cavidades, canais e } \\
\text { intergranulares complexos }\end{array}$ & $\begin{array}{l}\text { Cavidades, canais, alvéol os } \\
\text { intergranulares complexos e } \\
\text { fissuras }\end{array}$ \\
\hline Origem & Litopórica & Litopórica e pedopórica & Litopórica e Pedopórica & Pedopórica e Litopórica \\
\hline Feições pedológicas (\%) & Ausentes & Presentes & Presentes & Presentes \\
\hline $\operatorname{Tipos}^{(5)}$ & & $\begin{array}{l}\text { Hipocutans - ferrans de } \\
\text { grãos e poros }\end{array}$ & $\begin{array}{l}\text { Cutans - Ferriargilans e } \\
\text { ferrans Glébula }\end{array}$ & $\begin{array}{l}\text { Cutans - Ferriargilans } \\
\text { e ferrans de grãos, poros, } \\
\text { agregados e fissuras }\end{array}$ \\
\hline Processos pedogenéticos & \multicolumn{2}{|c|}{$\begin{array}{l}\text { Lixiviação ("box works"), Pseudomorfose, Ferruginização, } \\
\text { Argilização (bissialitização, monossialitização) }\end{array}$} & \multicolumn{2}{|c|}{$\begin{array}{l}\text { Lixiviação ("box works"), Pseudomorfose, Ferruginização, } \\
\text { Argilização (bissialitização, monossial itização), Iluviação }\end{array}$} \\
\hline Grau de pedalidade & Fraco & Moderado & Moderado & Moderada a forte \\
\hline $\begin{array}{l}\text { Decorrente de reações } \\
\text { etrógradas. }{ }^{(3)} \text { Segund } \\
\text { A = Diopsídio-Augita } \\
\text { t = Sericita; } \mathrm{Cl}=\text { Clorit } \\
\text { elictuais à alteração m }\end{array}$ & ops e J & ther & $\begin{array}{l}\text { nórficas). }{ }^{(2)} \text { Decorrentec } \\
\text { ). Pettijohn (1949). }{ }^{(5)} \mathrm{S} \\
=\text { Quartzo; TA = Tremc } \\
\text { ita. SFeTi = Sesquióxido }\end{array}$ & $\begin{array}{l}\text { ubstituições mineralógic } \\
\text { ndo Bullock et al. (198 } \\
\text {-Actinolita; U = Urali }\end{array}$ \\
\hline
\end{tabular}


Observando a evolução nos processos de alteração, a estrutura plásmica passa de crística a omnissépica do alterito ao sólum, e a distribuição relativa passa de quitônica/porfírica fechada a porfírica aberta (Quadro 5 eFigura 3c-f). Os processos de substituição mineralógica, destacando-se a pseudomorfose, mostram atuação de hidrólise dos minerais silicatados primários, com bissialitização (dessilicatização limitada, com formação de argilominerais 2:1 - esmectita) e monossialitização (dessilicatização moderada, com formação de argilominerais 1:1 - caulinita), porém não atingindo a alitização (dessilicatização completa, com formação de gibbsita). A hidrólise é rápida, com destruição de todos os minerais silicatados primários, porém de intensidade moderada, em virtude do excessivo suprimento de soluções ricas em $\mathrm{Si}^{4+}, \mathrm{Al}^{3+}, \mathrm{Mg}^{2+} \mathrm{eFe}^{2+}$, provenientes destas reações de hidról ise. A liberação do ferro por meio de hidrólise e oxidação favorece o processo de ferruginização crescente ao longo do perfil, favorecida pela composição mineralógica da rocha original, enriquecida nesteel emento(Quadro 2).

Os processos de lixiviação e pseudomorfose são acentuados. A presença de box works proporciona ao sólum o acréscimo de vazios, favorecendo o desenvolvimento da pedalidade, atingindo grau de moderado a forte. A ocorrência de ferriargilans e ferrans (Quadro 5 e Figura 3e ef) é favorecida pela composição plásmica e é indicativa do processo de iluviação de argila, anteriormente caracterizado por Lacerda (1999) na identificação dos atributos diagnósticos desta classe de solo.

A análise da substituição mineralógica ao longo do perfil permitiu estabelecer a seqüência de destruição intempérica dos minerais silicatados primários ao longo do processo de alteração, em concordância com outros autores em estudos similares, dentre eles Oliveira (1980), na seguinte ordem: Clinopiroxênio (Diopsídio-Augita) - Anfibólio (Hornblenda-E denita) - Anfibólio (TremolitaActinolita/U ralita) - Sericita - Plagioclásio.

\section{CONCLUSÕES}

1. A análise micropedológica, associada à caracterização petrográfica do material originário, ao longo dos três perfis de solos analisados (PVAd, PVe e MTf), permitiu avaliar as distinções na evolução dos processos de alteração em solos com horizonte $B$ textural, desenvolvidos a partir de material de origem de composição geoquímica distinta (ácida, intermediária e básica), na região de Lavras (MG).

2. A investigação realizada mostrou a rel evância de estudos de correlação entre materiais de origem geoquímica e petrologicamente individualizados e respectivas classes de sol os com horizonte B textural formadas.
3. A seguinte ordem de destruição intempérica dos minerais silicatados primários foi estabelecida ao longo dos perfis estudados: Perfil - 1 (PVAd): Anfibólio (H ornblenda-Edenita) - Carbonato Plagioclásio - Titanita - Epidoto/Clorita/Biotita Moscovita - Sericita - Fel dspato potássico; Perfil - 2 (PVe): Anfibólio (Hornblenda-E denita) - Plagioclásio - Titanita - Clorita/E pidoto/Biotita - Sericita; Perfil3 (MTf): Clinopiroxênio(Diopsídio-Augita) - Anfibólio (Hornblenda-Edenita) - Anfibólio (TremolitaActinolita/Uralita) - Sericita - Plagioclásio.

\section{LITE RATURA CITADA}

ANDRADE, H.; ALVES, H.M.R.; VIEIRA, T.G.C.; RESENDE, R.J .T.P.; ESTEVES, D.R; BRASIL, J .P.K. \& ROSA, E.R. Diagnóstico ambiental do município de Lavras com base em dados georreferenciados do meio físico: IV - Principais grupamentos de solos. In: CONGRESSO BRASILEIRO DE ENGENHARIA AGRíCOLA, 27, Poços de Caldas, 1998. Anais. Poços de Caldas, Universidade Federal de Lavras/ Sociedade Brasileira de Engenharia Agrícola, 1998. v.4. p.442-443.

BESOAIN, E. Mineralogía de arcillas de suelos. San J osé, Costa Rica, Instituto Interamericano de Cooperacion para la Agricultura, 1985. 1205p.

BREWER, R. Fabric and mineral analysis of soils. New York, J ohn Wiley, 1964. 470p.

BROWN, G. TheX-ray identification and crystal structure of clays minerals. London, London Mineralogical Society, 1961. $544 p$.

BULLOCK, P.; FEDOROFF, N.;J ONGERIUS, A.; STOOPS, G. \& TURSINA, T. Handbook for soil thin section description. England, Waine Resarch Publications, 1985. 150p.

CADY, J.G.; WILDING, L.P. \& DREES, L.R. Petrography microscope techiniques. In: KLUTTE, A., ed. Methods of soil analysis - Part 1 Physical and mineralogical methods. 2.ed. Madison, Soil Science Society of America, 1986. p.185218.

CASTRO, S.S. Sistemas detransformação pedológica em Marília, SP: B latossólicos e B texturais. São Paulo, Universidade de São Paulo, 1989. 274 p. (Tese de Doutorado)

CERRI, C.C. Alteração e pedogênese em áreas graníticas situadas sob diferentes condições bioclimáticas encontradas no Brasil. São Paulo, Universidade de São Paulo, 1979. 241p. (Tese de Doutorado)

EMPRESA BRASILEIRA DE PESQUISA AGROPECUÁRIA EMBRAPA. Centro Nacional de Pesquisa de Solos. Sistema brasileiro de classificação de solos. Brasília, EMBRAPA Serviço de Produção da Informação; Rio de J aneiro, EMBRAPA Solos, 1999. 412p.

GRIM. R.F. Clay mineralogy. 2.ed. New York, McGraw Hill, 1968. $596 \mathrm{p}$.

JOINT COMMITTE ON POWDER DIFFRACTION STANDARDS. Selected powder diffraction data for minerals. Pensylvania, 1974. 833p. 
LACERDA, M.P.C. Correlação geo-pedológica em solos B texturais na região de Lavras (MG). Lavras, Universidade Federal de Lavras, 1999. 257p. (Tese de Doutorado)

LOUGHNAN, F. C. Chemical weathering of thesilicateminerals. New York, Elsevier, 1969. 154p.

MEHRA, O.P. \& J ACKSON, M.L. I ron oxide removal from soils and clays by a dithionite-citrate system buffered with sodium bicarbonate. Clay Clay Mineral., 7:317-327, 1960.

MENEGOTTO, E. \& GASPARETO, N.V.L. Intemperização de rochas vulcânicas básicas eácidas na região de Santa Maria - RS. In: CONGRESSO BRASILEIRO DE GEOQUÍMICA, 1, Porto Alegre, 1987. Anais. Porto Alegre, Sociedade Brasileira de Geoquímica, 1987. v.2. p.69-87.

OLIVEIRA, S.M.B. Alteração intempérica das rochas ultrabásicas deSanta Fé(GO) egênese do depósito niquelífero. SãoPaulo, Universidade de São Paulo, 1980. 216p. (Tese de Doutorado)
PETTIJ OHN, F.J. Sedimentary rocks. New York, Harper Brothers, 1949. 526p.

QUÉMÉNEUR, J J.G. Os magmatismos de idade arqueana e transamazônica na região Campos das Vertentes (MG) (Sul do Cráton do São Francisco), com base em geoquímica e geocronologia. Belo Horizonte, CPMTC-IGC-UFMG, 1995. 79p. (Relatório inédito)

STOOPS, G. \& J ONGERIUS, A. Proposal for micromorphological classification of soil materials. I. A classification of the related distribution of coarse and fine particles. Geoderma, 13:189199, 1975

WHITTIG, L. D. \& ALLARDICE, W. R. X-ray diffration techniques. In: KLUTE, A., ed. Methods of soil analysis. Part 1 - Physical and mineralogical methods. 2.ed. Madison, Soil Science Society of America, 1986. (Agronomy, 9) 
M. P. C. LACERDA et al. 